\section{Introduction of photodynamic therapy for the treatment of neovascular age- related macular degeneration: tracking a moving target}

B Foot ${ }^{1,2}$, R Foy ${ }^{3}$, U Chakravarthy ${ }^{3}$ and R Wormald ${ }^{2}$

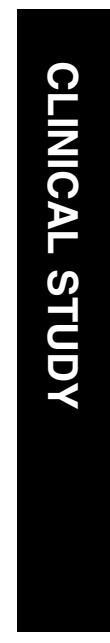

the 12-month period. The differing thresholds at which introduction of PDT would be considered justifiable varied widely. PDT is being introduced into the NHS in a fragmented manner. In common with other new health technologies, factors other than the strength of evidence appear to be influencing beliefs about the effectiveness of PDT and its subsequent provision. While it is unlikely that such an action alone will lead to evidencebased practice, the variations in beliefs identified by this survey suggest that sufficient clinical uncertainty exists to support the need for further clinical trials.

Eye (2003) 17, 583-586. doi:10.1038/

sj.eye. 6700459

Keywords: photodynamic therapy; service provision; health technology

\section{Introduction}

Neovascular age-related macular degeneration (AMD) causes severe visual loss. The randomised controlled trial on the treatment of AMD with photodynamic therapy (PDT) indicated that multiple treatments with verteporfin reduce the relative risk of losing three or more lines of visual acuity over 2 years. ${ }^{1,2}$ In particular, a subgroup analysis showed a highly statistically significant benefit in the prevention of visual loss in those subjects with wholly or predominantly classic choroidal neovascularization (CNV). These findings have contributed to pressure upon the NHS from both patient and professional groups to make
${ }^{1}$ The Royal College of Ophthalmologists London

${ }^{2}$ Research and Development Department Moorfields Eye Hospital London, UK

${ }^{3}$ Department of Reproductive and Development Sciences University of Edinburgh Edinburgh, UK

${ }^{4}$ Department of Ophthalmology Queen's University and Royal Victoria Hospitals Belfast, UK

Correspondence:

B Foot

Research and Development

Department

Moorfields Eye Hospital

City Road

Tel.: + 442075662823 or

07808581659

E-mail: barny.foot@

moorfields.nhs.uk

Received: 9 August 2002 Accepted: 19 November 2002

Conflicts of interest: None
London EC1V 2PD UK 
this therapy routinely available. ${ }^{3,4}$ However, Cochrane reviewers and commissioned experts for the influential 'Drug and Therapeutics Bulletin' have expressed reservations about the reliance placed on the subgroup analysis ${ }^{5}$ and the cost-effectiveness of PDT has been challenged. ${ }^{6}$ Furthermore, neither the treatment of age-related macular degeneration with photodynamic therapy (TAP) trial nor verteporfin in photodynamic therapy (VIP) trial has published patient-centred outcome data or evaluated cost-effectiveness. It has been estimated that the cost to treat only those patients with wholly classic $\mathrm{CNV}$ who are likely to number approximately 1000 per year would be of the order of $£ 8.3$ million. This cost would be five times greater if all patients with predominantly classic membrane disease were also treated. Concerns over clinical and costeffectiveness prompted the National Institute for Clinical Excellence (NICE) to undertake a technology appraisal of PDT for neovascular AMD.

Initial variations in referral and treatment of PDT, and beliefs about its effectiveness among clinical directors of ophthalmology services in the UK have been reported. ${ }^{7}$ Most notably, there was no clear consensus over what level of the treatment effect represented a worthwhile clinical benefit. Through two surveys conducted a year apart, we investigated changes in the treatment provision and beliefs within ophthalmology units in NHS hospitals in the UK.

\section{Methods and subjects}

We conducted two postal surveys of all clinical directors or lead consultants in NHS ophthalmology units within the UK. The units were identified using the Royal College of Ophthalmologists' database. The surveys were conducted in the autumns of 2000 and 2001. One reminder was sent to nonrespondents. We asked about the local treatment and referral policies for neovascular AMD and the threshold of clinical benefit considered sufficient to justify the use of PDT. The benefit was rated on the basis of the number of patients that would require treatment to prevent the loss of three lines of visual acuity for 2 years for one patient at a given fixed cost of treatment of $£ 8000$ per patient (known as number needed to treat (NNT)). This cost was estimated from the TAP study treatment protocol. ${ }^{1}$ Six options for the NNTs were presented: four based upon the point estimate of effect and upper and lower limits of the 95\% confidence intervals reported in the Cochrane Review, ${ }^{5}$ and two further categories of one in 50 and one in 100 for comparative purposes. The questionnaire had previously been pretested and modified to ensure that respondents understood the terms used. ${ }^{7}$
Changes in service provision and beliefs were analysed using the $\chi^{2}$-test, $\chi^{2}$-test for trend for ordinal data and McNemars $\chi^{2}$ for paired data. $P$-values are presented.

\section{Results}

Out of 152 questionnaires sent, 124 (82\%) and 120 (79\%) were returned for the baseline and follow-up surveys, respectively. Two clinical directors changed during the year. A total of 100 units responded to both surveys. No variations in the response rate were detected by health region $(P=0.82)$ or hospital teaching status $(P=0.67)$.

\section{Levels of service provision}

Between the surveys, the proportion of units routinely offering PDT for patients with more than $50 \%$ classic $\mathrm{CNV}$ almost trebled, and the overall availability of PDT on the NHS had increased $\left(\chi^{2}=23.08, \mathrm{df}=3, P<0.001\right)$ (Table 1). Changes in the pattern of service provision in the 100 units responding to both surveys are similar (McNemars $\chi^{2}=5.40, \mathrm{df}=1, P=0.02$ ). Table 2 shows how unit policies often shifted incrementally among different levels of provision.

\section{Threshold of clinical benefit}

Over the period between the two surveys, there was a significant reduction in the threshold of effectiveness at which respondents would support the use of PDT $\left(\chi_{\text {trend }}^{2}=6.24, \mathrm{df}=1, P=0.012\right)$. The proportion requiring further evidence before supporting the use of PDT decreased from 33 to $19 \%\left(\chi^{2}=6.4, \mathrm{df}=1, P=0.012\right)$. Among units responding to both surveys, the threshold of clinical benefit sufficient to justify treatment fell (McNemars $\chi^{2}=6.81, \mathrm{df}=1, P=0.01$ ) (Table 3).

Lower thresholds supporting the use of PDT were associated with greater reported provision at baseline

Table 1 Distribution of service provision

\begin{tabular}{lcc}
\hline Level of treatment using PDT offered & $\begin{array}{c}\text { Baseline survey } \\
2000\end{array}$ & $\begin{array}{c}\text { Follow up } \\
\text { survey 2001 }\end{array}$ \\
\hline $\begin{array}{l}\text { Routine provision for patients with } \\
\text { more than 50\% classic subfoveal }\end{array}$ & $10(8 \%)$ & $28(23 \%)$ \\
CNV & $38(31 \%)$ & $45(38 \%)$ \\
$\begin{array}{l}\text { Individual case decided upon } \\
\text { merits }\end{array}$ & $33(27 \%)$ & $9(8 \%)$ \\
$\begin{array}{l}\text { Referral to the private sector } \\
\text { No patients to be referred or } \\
\text { treated }\end{array}$ & $43(35 \%)$ & $38(32 \%)$ \\
Total & 124 & 120 \\
\hline
\end{tabular}


Table 2 Linked distribution of service provision

\begin{tabular}{|c|c|c|c|c|c|}
\hline \multirow[t]{2}{*}{ Provision in October 2000} & \multicolumn{5}{|c|}{ Provision in October 2001} \\
\hline & $\begin{array}{c}\text { Routine } \\
\text { provision for } \\
\text { patients with } \\
\text { more than } 50 \% \\
\text { classic subfoveal } \\
\text { CNV }\end{array}$ & $\begin{array}{l}\text { Individual case } \\
\text { decided upon } \\
\text { merits }\end{array}$ & $\begin{array}{c}\text { No. of patients } \\
\text { to be referred } \\
\text { or treated }\end{array}$ & $\begin{array}{l}\text { Referral to the } \\
\text { private sector }\end{array}$ & Total \\
\hline $\begin{array}{l}\text { Routine provision for patients with more } \\
\text { than } 50 \% \text { classic subfoveal CNV }\end{array}$ & 7 & 1 & 0 & 0 & 8 \\
\hline Individual case decided upon merits & 6 & 17 & 10 & 3 & 36 \\
\hline No patients to be referred or treated & 8 & 9 & 13 & 1 & 31 \\
\hline Referral to the private sector & 2 & 13 & 7 & 3 & 25 \\
\hline Total & 23 & 40 & 30 & 7 & 100 \\
\hline
\end{tabular}

Table 3 Threshold of clinical benefit to justify the use of PDT

\begin{tabular}{|c|c|c|c|}
\hline $\begin{array}{l}\text { Threshold of clinical benefit that } \\
\text { would make offering } \\
\text { PDT as a treatment worthwhile }\end{array}$ & & $\begin{array}{c}\text { Baseline survey } \\
2000\end{array}$ & $\begin{array}{c}\text { Follow-up survey } \\
2001\end{array}$ \\
\hline To achieve the prevention of loss & In at least one person for every seven treated & $22(19 \%)$ & $30(28 \%)$ \\
\hline of three lines of visual acuity over & In one person for every four treated & $35(30 \%)$ & $38(35 \%)$ \\
\hline 2 years & In one person for every two treated & $21(18 \%)$ & $20(19 \%)$ \\
\hline Further evidence of effectiveness required & & $39(33 \%)$ & $20(19 \%)$ \\
\hline Total & & 117 & 108 \\
\hline
\end{tabular}

$\left(\chi^{2}=20.4, \mathrm{df}=8, P=0.01\right)$ and follow-up $\left(\chi^{2}=25.2\right.$, $\mathrm{df}=8, P=0.003)$.

\section{Discussion}

Initially, there was substantial scepticism among ophthalmologists on the potential value of PDT. The first survey found clinicians requiring a higher threshold for benefit before supporting PDT and a lower level of service provision. The subsequent publication of the 2-year results from the TAP study and the results from the VIP study did not answer the questions concerning the evidence of effectiveness. ${ }^{5}$ So it was noteworthy that despite the absence of any significant new evidence supporting the use of PDT, the policies for referral and treatment, and beliefs about what represents a worthwhile clinical benefit changed significantly over 12 months. In common with other health technologies, factors other than the strength of evidence appear to be influencing beliefs about the effectiveness of PDT. ${ }^{8}$ These may include increasing familiarity with a new technique and successful 'marketing' by its proponents. ${ }^{9}$ Such factors may have contributed to the shift in consensus over what would represent an acceptable level of clinical benefit to justify the use of PDT.

A range of factors may influence the introduction of $\mathrm{PDT}^{8}$ such as the time required to secure funding and to develop new services. We also found evidence to suggest that support for the use of PDT at a lower threshold of clinical benefit is associated with more widespread provision. It is not known to what degree beliefs have influenced provision or provision influenced beliefs.

The reported variations in provision and perceptions of benefit from PDT indicate a need for guidance for a more objective approach to the introduction of PDT. However, PDT has been introduced into the NHS in a fragmented manner in advance of the NICE health technology appraisal. Furthermore, it is difficult to withdraw health-care interventions that are subsequently shown to be less effective once they have become established in routine practice. ${ }^{9}$ The growing acceptance and provision of PDT poses a problem to any position that may be taken by NICE and those seeking to implement its guidance. The continuing lack of consensus on what constitutes a worthwhile benefit and the inconsistency of service provision enable both proponents and opponents of PDT to retain sufficient 
ground for disputing the conclusions of the appraisal. The case for further clinical trials to provide more reliable estimates of the effectiveness of PDT has been made elsewhere. ${ }^{5}$ Future appraisals of PDT (as with all new interventions) should now be preceded by the development of a consensus over what constitutes a clinically important degree of benefit, and recognise the need to consult more widely than solely

ophthalmologists. ${ }^{10}$

Trials often encounter recruitment problems when preceded by widespread acceptance of an intervention. ${ }^{11}$ The variations in beliefs identified by this survey suggest that sufficient clinical uncertainty exists to support a further trial. While it is unlikely that such an action alone will lead to evidence-based practice, the trends towards growing adoption of PDT indicates that such a trial is more likely to be successfully completed if conducted sooner rather than later.

\section{Acknowledgements}

We are grateful to all the clinical directors who returned questionnaires.

\section{References}

1 TAP Study Group. Photodynamic therapy of subfoveal choroidal neovascularization in age-related macular degeneration with verteporfin One-year results of 2 randomized clinical trials. TAP report 1. Arch Ophthalmol 1999; 117: 1329-1345.

2 Bressler NM. Treatment of Age-Related Macular Degeneration with Photodynamic Therapy (TAP) Study
Group. Photodynamic therapy of subfoveal choroidal neovascularization in age-related macular degeneration with verteporfin: two-year results of 2 randomized clinical trials-tap report 2. Arch Ophthalmol 2001; 119(2): 198-207.

3 Bressler NM. Age-related macular degeneration. New hope for a common problem comes from photodynamic therapy. BMJ 2000; 821: 1425-1427.

4 NHS delays 'causing blindness' http://news.bbc.co.uk/hi/ english/health/newsid_1678000/1678779.stm

5 Wormald R, Evans J, Smeeth L. Photodynamic therapy for neovascular age-related macular degeneration (Cochrane review). In: Cochrane Library, 1: Software Update: Oxford, 2001.

6 Sharma S, Brown GC, Brown MM, Hollands H, Shah GK. The cost-effectiveness of photodynamic therapy for fellow eyes with subfoveal choroidal neovascularization secondary to age-related macular degeneration. Ophthalmology 2001; 108(11): 2051-2059.

7 Foot B, Foy R, Chakravarthy U, Wormald R. A new health technology: where is the consensus on a clinically worthwhile benefit? Eye 2002; 16(4): 469-471.

8 Rosen R, Gabbay J. Linking health technology assessment to practice. BMJ 1999; 319: 1292.

9 Mowatt G, Bower DJ, Brebner JA, Cairns JA, Grant AM, Mckee L. When and how to assess fast-changing technologies: a comparative study of medical applications of four generic technologies. Health Technol Assess 1997; 1(14): 1-149.

10 Steel N. Thresholds for taking antihypertensive drugs in different professional and lay groups: questionnaire survey. BMJ 2000; 320: 1446-1447.

11 Prescott RJ, Counsell CE, Gillespie WJ, Grant AM, Russell IT, Kiauka S. Colthart IR, Ross S, Shepherd SM, Russell D. Factors that limit the quality, number and progress of randomised controlled trials. Health Technol Assess 1999; 3(20). 